\title{
Oxygen Saturation Monitoring Using Resonance Raman Spectroscopy
}

Short title: Oxygen Saturation and Raman Spectroscopy

Ivo Torres Filho MD, PhD, ${ }^{1,2,3}$ Nguyen M. Nguyen, ${ }^{1}$ Rizwan Jivani, ${ }^{1}$ James Terner, $\mathrm{PhD},{ }^{4}$ Padraic Romfh, ${ }^{5}$ Daryoosh Vakhshoori, PhD, ${ }^{5}$ Kevin R. Ward, MD ${ }^{6}$

1) Department of Anesthesiology: Virginia Commonwealth University and the Virginia Commonwealth University Reanimation Engineering Science Center, Richmond, VA

2) Department of Emergency Medicine: Virginia Commonwealth University and the Virginia Commonwealth University Reanimation Engineering Science Center, Richmond, VA

3) Damage Control Resuscitation: U.S. Army Institute of Surgical Research, Fort Sam Houston, TX

4) Department of Chemistry: Virginia Commonwealth University and the Virginia Commonwealth University Reanimation Engineering Science Center, Richmond, VA

5) Pendar Medical, Cambridge, MA

6) Department of Emergency Medicine and the Michigan Center for Integrative Research in Critical Care: University of Michigan

Ivo Torres Filho: ivo.p.torres.civ@mail.mil

Nguyen M. Nguyen: nmn25.gu@gmail.com

James Terner: jterner@vcu.edu

Rizwan Jivani: jivani.rizwan@ gmail.com

Padraic Romfh: promfh@ pendarmedical.com

Daryoosh Vakhshoori: dvakhshoori@pendarmedical.com Kevin R. Ward: keward@umich.edu

AUTHOR CONTRIBUTIONS: I.T.F. and K.R.W. designed the study. M.N.M. and R.J. performed the research. J.T., P.R. and D.V. contributed with critical aspects on Raman spectroscopy. I.T.F, M.N.M., and R.J. analyzed the data. I.T.F. drafted the paper. All authors critically reviewed the manuscript.

Address for Information or Reprints and Corresponding Author:

Ivo Torres Filho, MD, PhD

Damage Control Resuscitation - U.S. Army Institute of Surgical Research

3698 Chambers Pass

Fort Sam Houston, TX 78234

Phone: 210-460-9744 Fax: 210-539-6244 E-mail: ivo.p.torres.civ@ mail.mil 


\begin{abstract}

\section{Background}

The knowledge of hemoglobin oxygen saturation $\left(\mathrm{SO}_{2}\right)$ and tissue oxygenation are critical to identify the presence of shock and therapeutic options. The resonance vibrational enhancement of hemoglobin allows measurement of oxy- and deoxy species of hemoglobin, and resonance Raman spectroscopy has been successfully used to measure aggregate microvascular oxygenation. We tested the hypothesis that non-invasive oxygen saturation measured by Resonance Raman spectroscopy (RRS-StO 2 ) could serve as surrogate of systemic central venous $\mathrm{SO}_{2}$.
\end{abstract}

\title{
Methods
}

In anesthetized rats, measurements of RRS-StO 2 made in oral mucosa, skin, muscle and liver were compared to measurements of central venous $\mathrm{SO}_{2}$ using traditional multiwavelength oximetry. Various oxygenation levels were obtained using a stepwise hemorrhage while over 100 paired blood samples and Raman-based measurements were performed. The relationships between RRS-StO 2 and clinically important systemic blood parameters were also evaluated. RRS-StO 2 measurements were made in $3 \mathrm{~mm}$ diameter tissue areas using a microvascular oximeter and a hand-held probe.

\section{Results}

Significant correlations were found between venous $\mathrm{SO}_{2}$ and $\mathrm{RRS}-\mathrm{StO}_{2}$ measurements made in the oral mucosa $(r=0.913, p<0.001)$, skin $(r=0.499, p<0.01)$, and liver $(r=0.611, p<0.05)$. The mean difference between sublingual $\mathrm{RRS}-\mathrm{StO}_{2}$ and blood sample $\mathrm{SO}_{2}$ values was $5.4 \pm 1.6 \%$. Sublingual RRS-StO 2 also correlated with lactate $(\mathrm{r}=0.909, \mathrm{p}<0.01)$, potassium $(\mathrm{r}=0.757$, $\mathrm{p}<0.01)$ and $\mathrm{pH}(\mathrm{r}=0.703, \mathrm{p}<0.05)$.

\section{Conclusions}

Raman-based oxygen saturation is a promising technique for the noninvasive evaluation of oxygenation in skin, thin tissues and solid organs. Under certain conditions, sublingual RRS$\mathrm{StO}_{2}$ measurements correlate with central venous $\mathrm{SO}_{2}$.

Keywords: oxygen saturation, Raman spectroscopy, shock, hemorrhage, tissue oxygenation 


\section{Introduction}

The non-invasive determination of tissue oxygenation is critical to identify the presence of shock and the suitability of therapeutic measures aimed at its resolution. The vibrational bands of heme proteins provide medically relevant information such as hemoglobin oxygen saturation $\left(\mathrm{SO}_{2}\right)$. Under proper excitation, the resonance vibrational enhancement of hemoglobin allows simultaneous identification and measurement of the proportion of oxy- and deoxy species of hemoglobin in a concentration dependent manner with a single excitation wavelength. A chemical fingerprint of the species can be obtained with little or no interference from other compounds.(1-3)

Because the profile of the microvasculature and blood volume in tissue is heavily weighted towards a venous composite (80\%), aggregate measures of tissue oxygenation are representative of the post-extraction compartment of tissues. In global shock states such as hemorrhage, tissue oxygenation from certain tissues may compare well to central measures such as central venous or mixed venous hemoglobin oxygen saturation. In previous studies from our group (1-3), resonance Raman spectroscopy has been successfully used to measure aggregate microvascular tissue oxygen saturation in the skin of normotensive rats using two laser excitations (406.7 and $532 \mathrm{~nm}$ ). Encouraging results were also found in large animal models of hemorrhagic shock.(4) 
In this study, we tested the hypothesis that non-invasive tissue oxygen saturation measured by Resonance Raman spectroscopy $\left(\mathrm{RRS}-\mathrm{StO}_{2}\right)$ could serve as surrogate of systemic central venous $\mathrm{SO}_{2}$. For this purpose, we compared non-invasive $\mathrm{RRS}-\mathrm{StO}_{2}$ measurements made in several different tissues (oral mucosa, skin, muscle and liver) with measurements of central venous $\mathrm{SO}_{2}$ using traditional multiwavelength $\mathrm{CO}$-oximetry. In order to provide a wide range of oxygenation levels, a protocol of stepwise hemorrhage was conducted while paired blood samples and Raman measurements were performed. We also evaluated quantitatively the relationship between RRS-StO ${ }_{2}$ and clinically important systemic blood parameters such as lactate and potassium. 


\section{Materials and Methods}

\section{Experimental Animals}

This study was approved by the Institutional Animal Care and Use Committee of Virginia Commonwealth University. We used 13 Sprague-Dawley rats (Harlan, Indianapolis, IN) weighing $241-501 \mathrm{~g}$. The rats were kept on a commercial diet with free access to drinking water, in a facility with constant temperature $\left(21-23^{\circ} \mathrm{C}\right)$ and humidity $(\sim 50 \%)$ that rotated through 12 hour light/dark cycles.

\section{Surgical Preparation}

The animals were anesthetized with $2 \%$ isoflurane and kept under constant anesthesia during cannulations $\left(1.5 \mathrm{~L} / \mathrm{min}\right.$ balance $\left.21 \% \mathrm{O}_{2}\right)$. The core temperature was maintained at $37^{\circ} \mathrm{C}$ using a thermostatically controlled heating blanket (Harvard Apparatus, Holliston, MA). A tracheostomy was performed to maintain a clear airway. The right jugular vein was cannulated with PE-90 tubing advanced to the entrance of the right atrium, used for the collection of blood samples and for injection of Euthasol at the end of the data acquisition process. The right femoral vein was cannulated with PE-50 tubing for infusion $\left(0.17-0.24 \mathrm{mg} / \mathrm{kg}^{-1} \mathrm{~h}^{-1}\right)$ of alfaxalone/alfadolone acetate (Saffan; Schering-Plough Animal Health, Welwyn Garden City, England) anesthesia by a microprocessor-controlled infusion/withdrawal syringe pump (model PHD 2000; Harvard Apparatus, Holliston, MA) once the experimental procedure began. The right femoral artery was cannulated with phosphate buffered saline (PBS) filled PE-50 tubing connected to a pressure transducer to continuously measure arterial blood pressure (AP), for the controlled-hemorrhage process, and for collection of blood samples. The AP was monitored using a pressure transducer connected to a computer for continuous data acquisition (DA100C, 
MP150, Acknowledge 3.9.0, Biopac Systems). All lines were flushed with heparinized PBS (10

i.u. $\mathrm{mL}^{-1}$ heparin) after each blood collection to inhibit clot formation. The vein and artery on the left side were not cannulated and this thigh was used for Raman monitoring.

\section{Resonance Raman Spectroscopy-based $\mathrm{O}_{2}$ Saturation Measurements (Figure 1)}

A microvascular oximeter (Pendar Medical, Cambridge, MA) was used to measure tissue oxygenation using resonance Raman spectroscopy. The device has a laser (405 nm, $4 \mathrm{~mW}$ ) coupled to a complex plastic fiber optic cable and a hand-held probe that illuminates a tissue area (approximately $3 \mathrm{~mm}$ in diameter, less than $1 \mathrm{~mm}$ deep). The oxy- and deoxy-hemoglobin molecules can be excited by the laser light into distinct vibrational states resulting in a differential wavelength shift of the scattered light. The charge-coupled device based spectrometer of the oximeter captures the spectrum of the scattered light every second, with distinct sharp peaks linearly proportional to the relative concentrations of oxy- and deoxyhemoglobin. The device contains dedicated software to calculate the RRS-StO 2 using the spectral peaks as the relative ratio of concentration of oxygenated hemoglobin to that of total hemoglobin.

\section{Animal Groups and Testing Sites}

Two groups of animals were studied. In one group of animals, the gracilis muscle, the sublingual surface and the surface of the paw were prepared for examination, as described below. In the second group of animals, the surface of the liver was prepared. The $\mathrm{RRS}-\mathrm{StO}_{2}$ readings were taken from each site by gently placing the Raman probe directly over each tissue area. In order to prepare the "Muscle" site, the left thigh was shaved and void of hair using a commercial hair removal cream. The skin layer was cut and folded back to expose the gracilis muscle that was immediately covered with Saran wrap to maintain the exposed tissue void of contact with 
atmosphere. PBS was administered (0.5 ml, i.v.) as a hydration fluid after exposure of the muscle. The site named "Oral" was prepared by manually opening the mouth of the rat to access the sublingual surface. The surface of the front paw was also utilized and the site named "Skin". A small portion of the liver was exposed by first removing the skin hair from the abdominal region and pulling this skin portion back. A cut was made at the linea alba just below the diaphragm and the abdominal muscles were folded back to expose a segment of the liver. Any small bleeding areas on the muscles were quickly cauterized and Saran wrap was placed over the entire exposed area. The Saran utilized was produced in 1999, and has been previously tested as a good barrier from contamination from room oxygen. The animals were then allowed time to stabilize (10-15 $\mathrm{min})$.

\section{Biochemistry and Baseline Measurements}

Blood samples from the femoral artery $(0.1 \mathrm{~mL}$ each $)$ were collected into heparinized glass capillary tubes (Clinitubes, Radiometer, Copenhagen, Denmark) and immediately replaced by an equal volume of heparinized PBS. Total hemoglobin concentration, hemoglobin $\mathrm{O}_{2}$ saturation, methemoglobin, and $\mathrm{O}_{2}$ content were measured with a multi-wavelength CO-oximeter (OSM3, Radiometer). Blood $\mathrm{pH}$, glucose, potassium, lactate, partial pressures of oxygen and carbon dioxide were measured with a blood gas analyzer (ABL 700; Radiometer, Copenhagen, Denmark). Immediately after $\mathrm{RRS}-\mathrm{StO}_{2}$ measurements, venous blood samples were drawn from the superior vena cava into capillary tubes. About 5 minutes later, a second set of baseline measurements was made.

\section{Hemorrhage}

The target hemorrhage volume was $45 \%$ of total blood volume (total BV was calculated as $6 \%$ of total body mass) and was achieved in 3 steps of $15 \%$ per blood withdrawal. Hemorrhage was 
performed manually and drawn from the right femoral artery line using a clean $5 \mathrm{ml}$ plastic syringe. Each step was followed by a 15 minute period for AP and heart rate to stabilize. After stabilization, $\mathrm{RRS}-\mathrm{StO}_{2}$ readings in each of the three sites and blood samplings were made. The process was repeated until the target hemorrhage volume was reached.

\section{Data Analysis}

The first step in the estimation of the $\mathrm{RRS}-\mathrm{StO}_{2}$ was the calculation of the peak ratio of the highest intensities of the Raman bands for oxygenated $\left(\mathrm{I}_{\mathrm{oxy}}\right)$ and deoxygenated $\left(\mathrm{I}_{\text {deoxy }}\right)$ hemoglobin at $1,360 \mathrm{~cm}^{-1}$ and $1,375 \mathrm{~cm}^{-1}$, respectively (Figure 1). The RRS-StO 2 was then estimated (in \%) using the peak ratio and adjustment coefficients previously obtained in calibration experiments. The spectra were analyzed with customized software specifically developed to streamline processing of Raman signals and estimate $\mathrm{RRS}-\mathrm{StO}_{2}$ on-line. As shown in Figure 1, 20-80 spectra were averaged in order to increase precision of the RRS-StO 2 determinations that were updated on the integrated monitor each second.

\section{Statistical Analysis}

Descriptive statistics are expressed as means \pm SEM. The coefficient of variation $(\mathrm{CV}$, calculated as mean divided by the standard deviation times 100) was used as an index of variability. Pearson correlation was used to quantify the degree to which any two variables are related. The statistical tests were performed using commercial computer software (OriginLab Origin 8 and Microsoft Excel 2010) and power analysis was performed for all correlations (Sigmaplot for Windows, v. 12.0). All P values correspond to two-tailed tests with significance set at 0.05 . 


\section{Results}

Anesthetized rats were studied before and during hemorrhagic hypotension. Under these conditions, progressive reductions in arterial pressure, local blood flow and oxygenation were observed. During baseline, all animals showed similar mean arterial pressure and heart rate, averaging $120.3 \pm 6.7 \mathrm{mmHg}$ and $415 \pm 10 \mathrm{~min}^{-1}$, respectively, which were lowered to $59.8 \pm 3.4$ $\mathrm{mmHg}$ and $393 \pm 15 \mathrm{~min}^{-1}$ after hemorrhage. A microvascular oximeter was used to make tissue oxygen saturation measurements based on the principles of resonance Raman spectroscopy using dedicated software (Figure 1). Immediately before and after $\mathrm{RRS}-\mathrm{StO}_{2}$ measurements, blood was sampled and analyzed using the CO-oximeter.

Table 1 summarizes the results of $\mathrm{SO}_{2}$ measurements made in all animals during baseline and after hemorrhagic hypotension. The Raman probe was manually and sequentially positioned on the surface of four tissues. A power analysis was performed for all correlations. The sample size and correlation coefficient averaged 23 and 0.6 , respectively, while a power of 0.8 was obtained for an alpha of 0.05. Measurements of $\mathrm{RRS}-\mathrm{StO}_{2}$ in the sub-lingual and liver surfaces showed significant correlation with venous $\mathrm{SO}_{2}$, and these tissues showed the smallest variability of RRS-StO 2 measurements. On average, $\mathrm{RRS}-\mathrm{StO}_{2}$ values estimated from Raman spectra in the liver were lower than $\mathrm{SO}_{2}$ values using blood samples by $11.0 \pm 3.4 \%$. Raman measurements in the surface of the exposed gracilis muscle showed the largest variability of $\mathrm{RRS}-\mathrm{StO}_{2}$ and no significant correlation with venous $\mathrm{SO}_{2}$. The correlation between $\mathrm{RRS}-\mathrm{StO}_{2}$ in the front paw (skin tissue) and venous $\mathrm{SO}_{2}$ was weaker but still statistically significant. 
The strong correlation between RRS-StO 2 values estimated from resonance Raman spectra in the sub-lingual surface and $\mathrm{SO}_{2}$ values measured from venous blood samples using a $\mathrm{CO}$-oximeter is presented in Figure 2. The mean difference between $\mathrm{RRS}-\mathrm{StO}_{2}$ values estimated from Raman spectra in this tissue and $\mathrm{SO}_{2}$ values using blood samples was $5.4 \pm 1.6 \%$.

The Raman-based $\mathrm{O}_{2}$ saturation values in the sublingual surface also correlated with various parameters measured in the blood collected from the vena cava (Figure 3): $\mathrm{RRS}-\mathrm{StO}_{2}$ was negatively correlated with blood lactate $(\mathrm{r}=0.909, \mathrm{p}<0.01)$ and potassium $(\mathrm{r}=0.757, \mathrm{p}<0.01)$, and positively correlated with $\mathrm{pO}_{2}(\mathrm{r}=0.910, \mathrm{p}<0.01)$ and $\mathrm{pH}(\mathrm{r}=0.703, \mathrm{p}<0.05)$. While the blood hemoglobin levels fell from a baseline of $14.2 \pm 1.1 \mathrm{~g} / \mathrm{dL}$ to $12.1 \pm 1.0 \mathrm{~g} / \mathrm{dL}$ during hemorrhage, the fraction of methemoglobin remained below $1 \%$. 


\section{Discussion}

Gas exchange takes place in vessels that contain most of the circulating blood: Arterioles, venules and capillaries (5). The Raman signal used for estimating $\mathrm{RRS}-\mathrm{StO}_{2}$ is a combination of arteriolar, capillary and venular $\mathrm{SO}_{2}$. The contribution will be proportional to the volumes of these vessels. Since most of the blood volume resides in capillaries and venules (5), the RRS$\mathrm{StO}_{2}$ mainly reflects the capillary and venular compartments. We tested the hypothesis that RRS$\mathrm{StO}_{2}$ could serve as surrogate of systemic venous $\mathrm{SO}_{2}$. Significant correlations were found between venous $\mathrm{SO}_{2}$ and $\mathrm{RRS}-\mathrm{StO}_{2}$ measurements made in the oral mucosa, skin, and liver.

In a swine model of hemorrhagic shock, we have recently shown that RRS-StO 2 measurements in the oral mucosa tracked simultaneous changes in central venous $\mathrm{SO}_{2}(4)$. Previous pilot studies (using large lasers and non-portable collection systems) have also indicated that mucosal RRS-StO 2 could track clinically relevant biochemical parameters such as lactate (6). In the present study, we confirm and expand those preliminary findings while providing quantitative data on the relationship between $\mathrm{RRS}-\mathrm{StO}_{2}$ and these parameters.

Although different regulatory mechanisms may partially explain dissimilarities in microand macro-hemodynamics, microvascular perfusion is also affected by local factors such as leukocyte adhesion, endothelial dysfunction, and rheological alterations. Nevertheless, since it can be imaged using minimally invasive methods $(7,8)$, the sublingual area has been investigated in experimental animals and humans. Its adequacy as a non-invasive site to study 
systemic changes has been demonstrated by various investigators $(9,10)$. Although RRS-StO 2 measurements have not been reported, decreases in microvascular flow indexes in sublingual microcirculation have been documented following hemorrhagic hypotension in pigs (11) and sheep (12). The reduction in functional vascular density of the sublingual mucosa matched the decreases in oxygen delivery in a model of progressive hemorrhage using human volunteers (13). In addition, the noninvasive assessment of mucosal microvascular perfusion and oxygenation may help to identify patients with potential need for fluid therapy in hemorrhage (14) and sepsis $(15,16)$. In this context, new methods of high specificity such as Raman spectroscopy, that provide RRS-StO2 estimations using simple algorithms (Figure 1) and backed by solid preclinical studies $(1-4,6)$ may offer ample potential clinical importance.

By utilizing low power deep violet laser excitation in a mucosal surface, the interfering resonance Raman signals of myoglobin from oral musculature were avoided due to only minimal penetration in this wavelength region. Moreover, low intensity excitation minimized sample degradation in a tissue not covered by the stratum corneum. The presence of a relatively thick epidermis did not prevent good RRS-StO ${ }_{2}$ measurements since a significant correlation between RRS-StO 2 from skin (paw) and venous $\mathrm{SO}_{2}$ was found (Table 1). While low-coherence spectroscopy has been used to estimate skin $\mathrm{SO}_{2}$ (17), those determinations were only preliminary and no attempts were made to correlate skin RRS-StO 2 with venous $\mathrm{SO}_{2}$.

A significant correlation between $\mathrm{RRS}-\mathrm{StO}_{2}$ from liver and venous $\mathrm{SO}_{2}$ was found (Table 1). These are the first data of $\mathrm{RRS}-\mathrm{StO}_{2}$ on liver. The fact that $\mathrm{RRS}-\mathrm{StO}_{2}$ in the liver were lower than central venous $\mathrm{SO}_{2}$ is not surprising as oxygenation changes in the splanchnic 
bed may change earlier and be more severe than is reflected in the aggregate measure of central venous $\mathrm{SO}_{2}$ (18). Moreover, the liver is mostly supplied with venous blood from the portal vein. Near-infrared spectroscopy (NIRS) has been used in the rat to study the effect of hypoxia on liver oxygenation and energy metabolism (19). In that study, the relationship between tissue and venous $\mathrm{SO}_{2}$ was not investigated, although in pigs a good correlation was found between tissue oxygenation measured by NIRS and $\mathrm{PO}_{2}$ in the hepatic vein (20). In children, NIRS was used transcutaneously (optode placed over the palpable liver) and the measurements did not correlate with $\mathrm{SO}_{2}$ measured from blood samples taken from the inferior vena cava (21). The authors pointed several reasons for the lack of correlation including the fact that the NIRS values were mainly determined by non-hepatic measures such as arterial saturation and vascular resistances. Although widely available, NIRS requires care in interpretation due to issues related to the biophysics of measurement and lack of a standard to validate the measurement. Like pulse oximetry, NIRS is based on the principle of relating light absorption to oxyHb and deoxyHb concentrations. For example, since optical path length and light scattering are not constant in adults or children $(22,23)$, it has been difficult to establish the exact error in the measurement because NIRS lacks a standard to compare it against.

We found no correlation between RRS-StO ${ }_{2}$ from muscle and central venous $\mathrm{SO}_{2}$. One possible explanation for this finding is that optical detection can be obscured by competing background signals, such as those from myoglobin in muscle tissue or other absorbing chromophores.(24-26) As with the respective NIR absorptions, we have previously observed that resonance Raman signals of myoglobin are similar to those of hemoglobin.(3) Therefore, these may have interfered with the estimations of RRS-StO ${ }_{2}$ from muscle. The fact that myoglobin 
and hemoglobin have significantly different P50 values, it is not surprising that signals contaminated with myoglobin may not reflect central venous $\mathrm{SO}_{2}$. The fact that the measurements cannot distinguish myoglobin and hemoglobin does not present a major limitation since a highly significant correlation was found between $\mathrm{RRS}-\mathrm{StO}_{2}$ and a clinically relevant site (sublingual mucosa). Moreover, using $405 \mathrm{~nm}$ excitation, Raman measurements in the most accessible area in the body (the skin) can be readily performed without any interfering signals from myoglobin in deeper tissue.

\section{Limitations and Applications}

While we tried to track changes in $\mathrm{RRS}-\mathrm{StO}_{2}$ and central venous $\mathrm{SO}_{2}$ over a wide range of oxygenation levels, we did not investigate levels reached near death or very high $\mathrm{SO}_{2}$ levels. Since animals were not resuscitated, the correlations are unknown during resuscitation using different fluids. Only one species (rats) was used, although the results are in complete agreement with data from pigs using the same methodology (4). A low power continuous laser beam was used to avoid harmful effects associated with intense pulsed laser beams since laser safety limits for the application of ultrashort pulses on human tissues are more stringent than those with continuous wave lasers(27). In addition to providing specific quantitative data on the relationship between $\mathrm{SO}_{2}$ and $\mathrm{RRS}-\mathrm{StO}_{2}$, this study shows the suitability of a device based on Raman spectroscopy for "point and shoot" oxygenation measurements in thin tissues and in solid organs, therefore valuable in multiple clinical settings. This is especially important since a recent study showed that an abnormal sublingual microvascular flow index was independently associated with an increased risk of hospital death in critically ill patients of 36 ICUs worldwide (28). Also, evaluations of sublingual microcirculation by physicians and nurses were highly sensitive and 
specific for sublingual microcirculatory abnormalities (29). A direct comparison between RRS$\mathrm{StO}_{2}$ and the sublingual microcirculation using methods such as sidestream dark field imaging (7), was outside the scope of the present work because SDF currently does not measure $\mathrm{O}_{2}$ saturation. Nevertheless, it is likely that $\mathrm{RRS}-\mathrm{StO}_{2}$ measurements will correlate with parameters derived from SDF images.

\section{Conclusion}

In summary, RRS-StO 2 is a promising technique for the noninvasive evaluation of oxygenation in various tissues such as sublingual mucosa, skin, and liver. The RRS-StO $\mathrm{S}_{2}$ measurements in the sublingual mucosa correlate with central venous $\mathrm{SO}_{2}$ and other relevant biochemical parameters such as lactate, potassium and $\mathrm{pH}$. Additional testing will be required to test its ability to track changes in tissue oxygenation during resuscitation. 


\section{ACKNOWLEDGEMENTS:}

The authors would like to thank Bruce Spiess, Brian Berger, and M. Hakam Tiba for the help during various phases of the study. The opinions or assertions contained herein are the private views of the author and are not to be construed as official or as reflecting the views of the Department of the Army or the Department of Defense. 


\section{Figure Legends}

Figure 1. Composite picture showing the display of the device used for estimating tissue oxygen saturation in the oral mucosa based on Raman spectroscopy $\left(\mathrm{StO}_{2}\right)$ during four levels of oxygenation (Panels A-D). The intensities of the strongest resonance Raman hemoglobin peaks, indicated by arrows (deoxyhemoglobin, $\mathrm{I}_{\mathrm{deoxy}}$ and oxyhemoglobin, $\mathrm{I}_{\mathrm{oxy}}$ ), vary as oxygenation level changes (as a consequence of hemorrhage). These intensities are used by the device to calculate $\mathrm{StO}_{2}$ as indicated by the formula on the left, and the result appears on each digital panel. Also shown is the formula used in the calculation of Raman shift where $\lambda_{\text {inc }}$ and $\lambda_{\text {scatt }}$ are the incident and Raman scattered light wavelengths (in $\mathrm{cm}$ ), respectively.

Figure 2. Values of oxygen saturation estimated from Raman spectroscopy $\left(\mathrm{StO}_{2}\right)$ and measured from venous blood samples using an oximeter $\left(\mathrm{SO}_{2}\right)$. The illustrated data are from probes positioned on the oral mucosa (sub-lingual surface) of 7 anesthetized rats. Each point represents a single saturation determination (Raman and oximeter). The least-squares regression was calculated considering measurements during baseline and after hemorrhage $(\mathrm{p}<0.001)$.

Figure 3. Values of oxygen saturation estimated from Raman spectroscopy $\left(\mathrm{StO}_{2}\right)$ and levels of different biochemical parameters from venous blood samples. A statistically significant correlation was found in all cases. Data obtained from 7 rats and include measurements during baseline and after hemorrhage. 
Table 1. Results of oxygen saturation measurements made in 4 different sites using Raman Spectroscopy and in venous blood samples from 10 animals during baseline and after hemorrhage.

\begin{tabular}{|c|c|c|c|c|c|}
\hline & \multirow{2}{*}{$\begin{array}{l}\text { Venous } \\
\mathrm{SO}_{2}(\%)\end{array}$} & \multicolumn{4}{|c|}{ Resonance Raman Spectroscopy $\mathrm{O}_{2}$ Saturation (\%) } \\
\hline & & Oral & Skin & Muscle & Liver \\
\hline Mean \pm SEM & $42.4 \pm 3.7$ & $47.9 \pm 2.9$ & $21.8 \pm 2.0$ & $63.7 \pm 4.2$ & $22.1 \pm 3.4$ \\
\hline $\mathbf{n}$ & 27 & 27 & 27 & 27 & 12 \\
\hline Range & $9.3-75.4$ & $18.0-77.0$ & $5.0-48.6$ & $6.0-88.0$ & $15.3-32.2$ \\
\hline CV (\%) & 45.1 & 31.5 & 48.0 & 88.0 & 27.5 \\
\hline $\mathrm{RRS} \mathrm{StO}_{2}$ vS. & ous $\mathrm{SO}_{2}$ & $r=0.913 * * *$ & $r=0.499 * *$ & $r=0.249$ & $r=0.611^{*}$ \\
\hline
\end{tabular}

$\mathrm{n}$, number of measurements; CV, coefficient of variation; SEM, standard error of mean. The correlation coefficients $(r)$ refer to least squares linear regressions between Raman-estimated oxygen saturations (RRS-StO${ }_{2}$ ) in each site and $\mathrm{CO}$-oximeter measured saturations using venous blood samples (last row). All correlation coefficients were statistically significant $(* * *=p<0.001$, $\left.{ }^{* *}=p<0.01, *=p<0.05\right)$, except for “Muscle" $(p=0.210)$. 
Figure 1

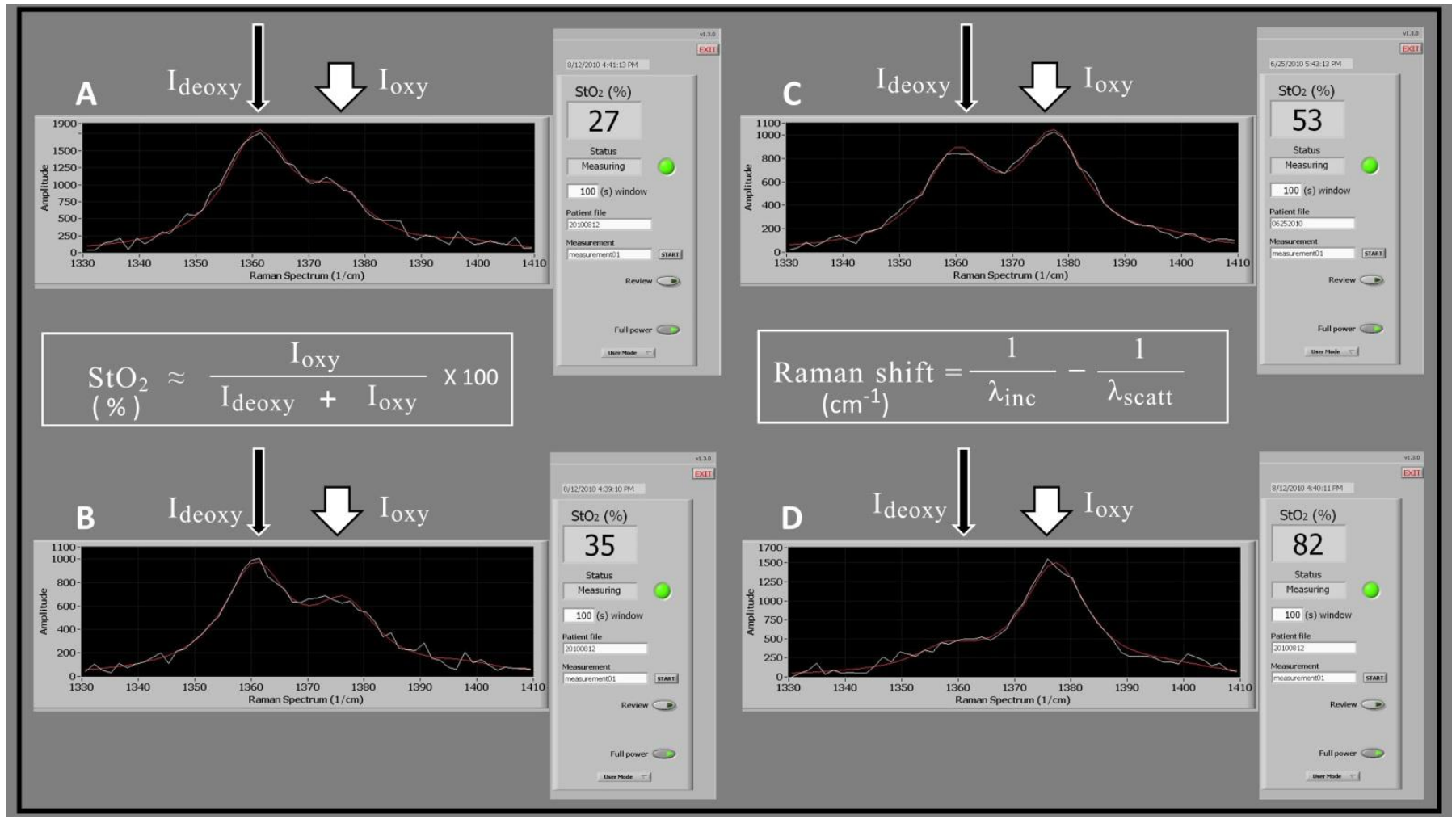


Figure 2

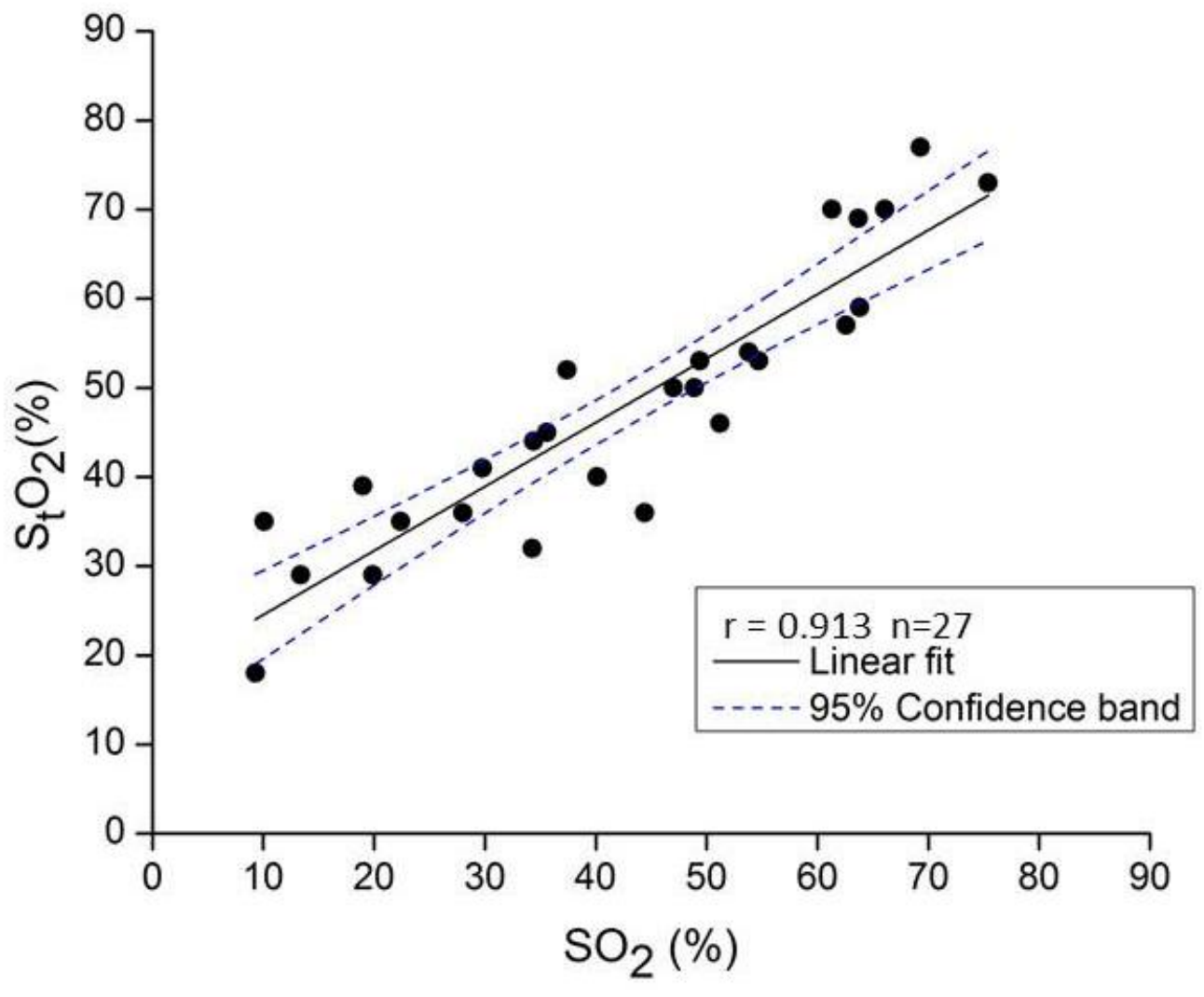


Figure 3
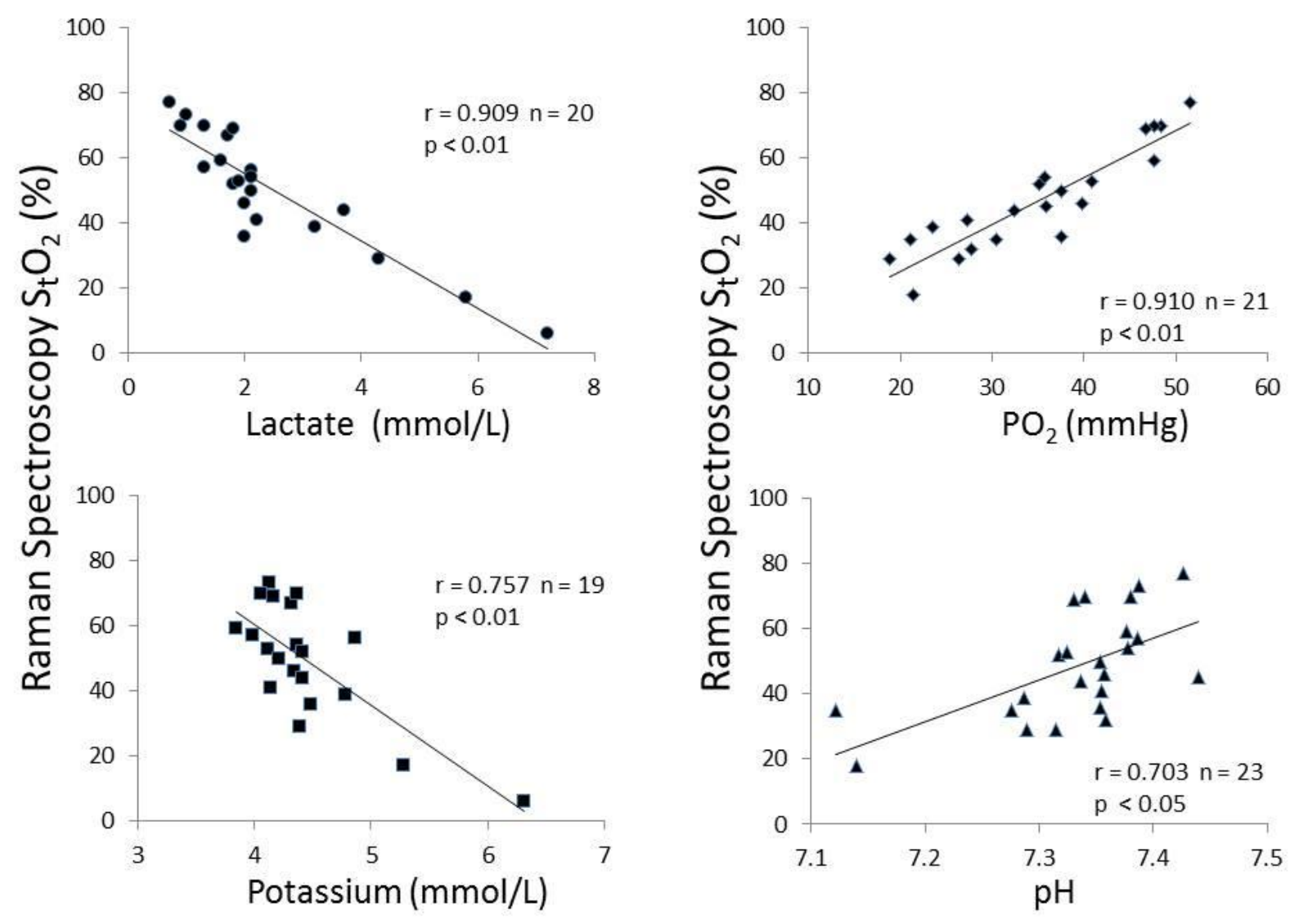


\section{References}

1. Torres Filho IP, Terner J, Pittman RN, Proffitt E, Ward KR Measurement of hemoglobin oxygen saturation using Raman microspectroscopy and 532-nm excitation. Journal of applied physiology 2008:104:1809-1817.

2. Torres Filho IP, Terner J, Pittman RN, Somera LG, 3rd, Ward KR Hemoglobin oxygen saturation measurements using resonance Raman intravital microscopy. American journal of physiology. Heart and circulatory physiology 2005:289:H488-495.

3. Ward KR, Barbee RW, Reynolds PS, Filho IP, Tiba MH, et al. Oxygenation monitoring of tissue vasculature by resonance Raman spectroscopy. Analytical chemistry 2007:79:15141518.

4. Tiba MH, Draucker GT, Barbee RW, Terner J, Filho IT, et al. Tissue oxygenation monitoring using resonance Raman spectroscopy during hemorrhage. The journal of trauma and acute care surgery 2014:76:402-408.

5. Wiedeman MP Dimensions of blood vessels from distributing artery to collecting vein. Circulation research 1963:12:375-378.

6. Ward KR, Torres Filho I, Barbee RW, Torres L, Tiba MH, et al. Resonance Raman spectroscopy: a new technology for tissue oxygenation monitoring. Critical care medicine 2006:34:792-799.

7. Goedhart PT, Khalilzada M, Bezemer R, Merza J, Ince C Sidestream Dark Field (SDF) imaging: a novel stroboscopic LED ring-based imaging modality for clinical assessment of the microcirculation. Optics express 2007:15:15101-15114.

8. Groner W, Winkelman JW, Harris AG, Ince C, Bouma GJ, et al. Orthogonal polarization spectral imaging: a new method for study of the microcirculation. Nature medicine 1999:5:12091212.

9. De Backer D, Dubois MJ Assessment of the microcirculatory flow in patients in the intensive care unit. Current opinion in critical care 2001:7:200-203.

10. Verdant CL, De Backer D, Bruhn A, Clausi CM, Su F, et al. Evaluation of sublingual and gut mucosal microcirculation in sepsis: a quantitative analysis. Critical care medicine 2009:37:2875-2881.

11. Maier S, Holz-Holzl C, Pajk W, Ulmer H, Hengl C, et al. Microcirculatory parameters after isotonic and hypertonic colloidal fluid resuscitation in acute hemorrhagic shock. The Journal of trauma 2009:66:337-345.

12. Dubin A, Pozo MO, Ferrara G, Murias G, Martins E, et al. Systemic and microcirculatory responses to progressive hemorrhage. Intensive care medicine 2009:35:556-564.

13. Ward KR, Tiba MH, Ryan KL, Filho IP, Rickards CA, et al. Oxygen transport characterization of a human model of progressive hemorrhage. Resuscitation 2010:81:987-993. 14. Pranskunas A, Koopmans M, Koetsier PM, Pilvinis V, Boerma EC Microcirculatory blood flow as a tool to select ICU patients eligible for fluid therapy. Intensive care medicine 2013:39:612-619.

15. Boerma EC, Mathura KR, van der Voort PH, Spronk PE, Ince C Quantifying bedsidederived imaging of microcirculatory abnormalities in septic patients: a prospective validation study. Critical care 2005:9:R601-606. 
16. Ospina-Tascon G, Neves AP, Occhipinti G, Donadello K, Buchele G, et al. Effects of fluids on microvascular perfusion in patients with severe sepsis. Intensive care medicine 2010:36:949-955.

17. Bosschaart N, Faber DJ, van Leeuwen TG, Aalders MC In vivo low-coherence spectroscopic measurements of local hemoglobin absorption spectra in human skin. Journal of biomedical optics 2011:16:100504.

18. Ba ZF, Wang P, Koo DJ, Cioffi WG, Bland KI, et al. Alterations in tissue oxygen consumption and extraction after trauma and hemorrhagic shock. Critical care medicine 2000:28:2837-2842.

19. Seifalian AM, El-Desoky H, Delpy DT, Davidson BR Effect of graded hypoxia on the rat hepatic tissue oxygenation and energy metabolism monitored by near-infrared and 31P nuclear magnetic resonance spectroscopy. FASEB journal : official publication of the Federation of American Societies for Experimental Biology 2001:15:2642-2648.

20. El-Desoky AE, Jiao LR, Havlik R, Habib N, Davidson BR, et al. Measurement of hepatic tissue hypoxia using near infrared spectroscopy: comparison with hepatic vein oxygen partial pressure. European surgical research. Europaische chirurgische Forschung. Recherches chirurgicales europeennes 2000:32:207-214.

21. Weiss M, Schulz G, Fasnacht M, Balmer C, Fischer JE, et al. Transcutaneously measured near-infrared spectroscopic liver tissue oxygenation does not correlate with hepatic venous oxygenation in children. Canadian journal of anaesthesia = Journal canadien d'anesthesie 2002:49:824-829.

22. Benaron DA, Kurth CD, Steven JM, Delivoria-Papadopoulos M, Chance B Transcranial optical path length in infants by near-infrared phase-shift spectroscopy. Journal of clinical monitoring 1995:11:109-117.

23. Duncan A, Meek JH, Clemence M, Elwell CE, Fallon P, et al. Measurement of cranial optical path length as a function of age using phase resolved near infrared spectroscopy. Pediatric research 1996:39:889-894.

24. Beilman GJ, Myers D, Cerra FB, Lazaron V, Dahms RA, et al. Near-infrared and nuclear magnetic resonance spectroscopic assessment of tissue energetics in an isolated, perfused canine hind limb model of dysoxia. Shock 2001:15:392-397.

25. Chance B, Wang NG, Maris M, Nioka S, Sevick E Quantitation of tissue optical characteristics and hemoglobin desaturation by time- and frequency-resolved multi-wavelength spectrophotometry. Advances in experimental medicine and biology 1992:317:297-304.

26. Nighswander-Rempel SP, Kupriyanov VV, Shaw RA Relative contributions of hemoglobin and myoglobin to near-infrared spectroscopic images of cardiac tissue. Applied spectroscopy 2005:59:190-193.

27. Matousek P, Draper ER, Goodship AE, Clark IP, Ronayne KL, et al. Noninvasive Raman spectroscopy of human tissue in vivo. Applied spectroscopy 2006:60:758-763.

28. Vellinga NA, Boerma EC, Koopmans M, Donati A, Dubin A, et al. International study on microcirculatory shock occurrence in acutely ill patients. Critical care medicine 2015:43:48-56.

29. Lima A, Lopez A, van Genderen ME, Hurtado FJ, Angulo M, et al. Interrater Reliability and Diagnostic Performance of Subjective Evaluation of Sublingual Microcirculation Images by Physicians and Nurses: A Multicenter Observational Study. Shock 2015:44:239-244. 